\title{
Antioxidant activity of orange peel powder in ghee at accelerated temperature
}

\author{
M Manjunatha, Chitranayak, Mahesh Kumar G, Khushbu Kumari, Anand BA and Vairat Amita D
}

Received: 03 December 2018 / Accepted: 11 January 2019 / Published online: 18 April 2019

(C) Indian Dairy Association (India) 2019

\begin{abstract}
Antioxidant potential of orange peel powder in ghee was demonstrated. Orange peel powder $(1,1.5$ and $2 \%)$ was added in to butter and prepared ghee and stored for accelerated storage study at $60 \pm 2^{\circ} \mathrm{C}$. Ghee with BHA $(0.02 \%)$ and control (without any additives) were also prepared, stored and analyzed for comparison during the study. Peroxide value and thiobarbuturic acid (TBA) of ghee samples stored at accelerated condition $\left(60^{\circ} \mathrm{C} \pm 2\right)$ were analyzed at 4 day interval during 16 day storage period. Peroxide value and TBA were observed to increase in all the samples with highest in the control. Increase in peroxide value was least in the sample treated with $2 \%$ orange peel powder whereas the sample treated with BHA was observed with lowest increase in TBA value. Orange peel powder can be utilized as a source of natural antioxidant for reducing oxidative deterioration in ghee.
\end{abstract}

Keywords: Antioxidant property, Ghee, Natural antioxidant, Orange peel powder, Shelf-life

India is the largest milk producer in the world and producing about 180 million tonnes per annum. About $35 \%$ of total milk production is converted in to ghee. Ghee is subjected to continuous and frequent heating for the purpose of cooking and

M Manjunatha

Agriculture Engineering, UAS, Bengaluru 560 030, India

Chitranayak $(\bowtie)$

Dairy Engineering Division, ICAR-NDRI, Karnal-132 001, India

E-mail: chitranayaksinha@gmail.com; Phone.: 8867192926

Mahesh Kumar G

Department of Dairy Engineering, DSC, Hebbal Bengaluru 560 065, India

Khushbu Kumari Anand BA and Vairat Amita D

Agriculture Engineering, UAS, Bengaluru560 065, India frying of various food products. Shelf life of ghee is about 6 to 10 months depending up on the packaging and storage conditions. If ghee is not stored in recommended packaging and storage conditions, it undergoes oxidative deterioration. Oxidative degradation processes include hydrolysis, oxidation and polymerisation followed by the formation of desirable and undesirable secondary products which affects both, ghee and finished product quality. The oxidation process in ghee affects its major quality parameters adversely resulting in poor consumer acceptance, which is actually due to the formation of undesirable end products in the oxidised ghee. The negative health implications of lipids oxidisation have been demonstrated in numerous literatures.

Various research works have showed that ghee undergoes oxidative deterioration during (Wasnik et al. 2017; Shende et al. 2014; Gandhi et al. 2013; Pawar et al. 2012) and the level of spoilage and degradation of ghee quality depends mainly on storage temperature, the availability of oxygen content and physical state of ghee due to more contact of oxygen with the ghee components which are under convection current under varied temperature than solid state ghee (Asha et al., 2015). The oxidative deterioration of ghee degrades its colour, flavour, aroma and nutritive value affects its suitability for consumption and reducing the shelf-life of the product (Choe and Min 2006; Gandhi et al. 2013; Pawar et al. 2012; Shende et al. 2014). There are numerous evidences which correlate the oxidized lipids with negative health implications (Pukalskas et al. 2005). Lipids and fat oxidation can be retarded or prevented by using antioxidants. More often synthetic antioxidants such as butylated hydroxytoluene (BHT), butylated hydroxyanisole (BHA), tertbutyl hydroquinone (TBHQ) and propyl gallate (PG) are used to retard oxidative deteriorations.

Many researchers have worked on the shelf life enhancement by the use of natural antioxidant and found that the orange peel extract can be used as natural antioxidant (Bombardelli and Morazzoni 1993) in corn oil (Rehman 2006); in soybean oil (Gharahkhani et al.2010; Abdelaal and Halaweish 2010); in canola oil (Yassari and Yasari 2013) for exhibiting the antioxidant activities. The rapid increase in use of natural antioxidants in food industry (Beddows et al. 2001) has attracted the researchers 
to extract natural antioxidants from citrus peels and the use of those natural and safe substances in foods for the purpose of preventing rancidity and inhibiting lipid oxidation (Anagnostopoulou et al. 2006; Peschel et al. 2006; Rehman 2006; Yassari and Yasari 2013).

The addition of antioxidants is a method of extending the shelf life, especially of lipids and lipid containing foods. Currently synthetic antioxidant BHA is permitted to prolong the shelf-life of ghee and in recent years there is a growing restriction in use of these synthetic antioxidants (AOAs) in foods as these are inappropriate for chronic human consumption, suspected to be carcinogenic effects and pose toxic effects on human health. Therefore, the importance of search for natural antioxidants, especially of plant origin, has immensely increased in recent years. India is the largest producer of fruits and vegetables and huge quantity of by-products is being generated during their processing. These by-products of fruits and vegetables were proved to be potential sources of natural antioxidants. The byproducts (powder or extract) of fruits containing natural antioxidants can be incorporated into fat rich dairy products like ghee for enhancing shelf-life and maintaining nutritional and sensory quality. Orange constitutes about $60 \%$ of the total citrus world production. A large portion of this production is addressed to the industrial extraction of citrus juice which leads to huge amounts of by-products, including peel and segment membranes. Orange peel represents between 50 to $65 \%$ of total weight of the fruits and remains as the primary by product. Orange peel is underutilized though it is good natural source of bioactive compounds. Orange peel is reported to be a potential source of bioactive compounds including antioxidants. Therefore, the present work was undertaken to study the antioxidant potential of orange peel powder in ghee.

Peeled peels were separated from fruit and sliced to reduce size for faster drying. The sliced pieces were dried using convective airdrier @ $50^{\circ} \mathrm{C}$ with 30 min interval. Dried peels were ground by mixer to obtain fine powder. The powder was immediately packed in low density polyethylene (LDPE) packaging and stored in deep freezer to preserve the antioxidant properties of powder for further use. Ghee was prepared using fresh cream ( $50 \%$ fat). Ripen cream was subjected to churning process using mixer. While mixing/churning of cream, ice water was added to maintain the temperature of about $15-17^{\circ} \mathrm{C}$. Churning was done in mixer for few minutes to get butter. Orange peel powder was added to butter and heated (clarification) for $15 \mathrm{~min}$ and butter was removed off the flame burner as soon the temperature reached $115^{\circ} \mathrm{C}$. The clarified ghee filtered and stored for analysis. The ghee samples added with different levels of orange peel powder. Ghee samples (control without adding either orange peel powder or BHA, orange peel powder and BHA) were prepared. Orange peel powder was added to butter@1,1.5 and 2\% by ghee weight and prepared ghee. BHA was added to butter @ 0.02\% (maximum recommended limit) by ghee weight. Required number of treated samples and control were prepared using conical flasks covered with stoppers and stored for analysis at $60 \pm 2^{\circ} \mathrm{C}$. Stored ghee samples were analyzed at different storage intervals for antioxidant properties. Peroxide content and thiobarbuturic acid (TBA) of ghee samples were determined by the method as described in IS:3508(1966). Nine point hedonic scale was followed for sensory evaluation. Sensory panelists were asked to score the samples from 1 to 9 [1=dislike extremely; 2 =dislike very much; $3=$ dislike moderately;

Table 1 Mean values of sensory attributes of ghee added with OPP and BHA

\begin{tabular}{lllll}
\hline Treatment & Color & Aroma & Taste & OA \\
\hline Control & 8.5 & 7.7 & 8.2 & 7.6 \\
OPP $(1 \%)$ & 8.4 & 7.7 & 8.1 & 8.0 \\
OPP $(2 \%)$ & 8.1 & 6.7 & 7.3 & 7.7 \\
OPP $(4 \%)$ & 6.9 & 6.2 & 6.6 & 6.7 \\
OPP $(8 \%)$ & 6.6 & 5.6 & 6.6 & 7.1 \\
OPP $(12 \%)$ & 6.0 & 5.3 & 5.8 & 6.3 \\
\hline
\end{tabular}

OPP: Orange peel powder; OA: Overall acceptability

Table 2 Peroxide values (millimoles of oxygen per g of fat) of ghee samples stored at $60 \pm 2^{\circ} \mathrm{C}$

\begin{tabular}{|c|c|c|c|c|c|}
\hline \multirow{2}{*}{ Treatment } & \multicolumn{5}{|c|}{ Storage period, days } \\
\hline & $\overline{0}$ & 4 & 8 & 12 & 16 \\
\hline Control & 0.0082 & 0.1511 & 0.3282 & 0.4678 & 0.5239 \\
\hline OPP(1\%) & 0.0000 & 0.0286 & 0.0820 & 0.2371 & 0.3689 \\
\hline OPP(1.5\%) & 0.0000 & 0.0205 & 0.0574 & 0.2213 & 0.3531 \\
\hline $\mathrm{OPP}(2 \%)$ & 0.0000 & 0.0123 & 0.0572 & 0.2130 & 0.3192 \\
\hline$\underline{\mathrm{BHA}(0.02 \%)}$ & 0.0000 & 0.0206 & 0.0739 & 0.2382 & 0.3688 \\
\hline
\end{tabular}

OPP: Orange peel powder; OA: Overall acceptability 
4=dislike slightly; $5=$ neither like nor dislike; $6=$ like slightly; $7=$ like moderately; $8=$ like very much; $9=$ like extremely].

Mean values of sensory attributes of ghee samples (control, added with OPP and BHA) are tabulated in the Table 1. It is clear from the Table 1 that the ghee samples added with $1 \%$ orange peel powder (OPP) was scored highest scores for color, aroma, taste and overall acceptability (OA) than all other treated samples except control. Sensory attributes of OPP $1 \%$ were very close to that of control. The OA of ghee sample with $1 \%$ OPP was highest among all the samples. Color, aroma, taste and overall acceptability (OA) values of ghee added with $2 \%$ orange peel

powder (OPP) were 8.1, 6.7, 7.3 and 7.7 and these values were more than the ghee samples added with 4 to $12 \%$ OPP but very close to the ghee added with $1 \%$ OPP. On the basis of preliminary sensory study OPP $(1,1.5$ and $2 \%)$ was added in to butter and prepared ghee and stored for storage study. Ghee with BHA $(0.02 \%)$ and control without any additives were also prepared and stored for comparison during the study. Antioxidant properties of OPP and BHA in ghee were analyzed and compared with control during the study.

The experimental data on peroxides due to lipid oxidation in ghee treated with orange peel powder and BHA in comparison with control ghee samples on the peroxides development are presented in the Table 2.

The peroxide value was not detected in all the treated ghee samples and the control was observed with slight development of peroxides on zero day. Development of peroxide was observed after 4 days in all the samples. Highest peroxide was observed in control whereas lowest was in the sample treated with $2 \%$ OPP followed by $1.5 \%$ OPP, BHA, and 1\% OPP. Similar trend was observed up to 12 days of storage. On $16^{\text {th }}$ day storage, $2 \%$ OPP continued show less development of peroxides where as control showed with highest increase in peroxides. Samples treated with $1.5 \%$ OPP, $1 \%$ OPP and BHA showed increase in peroxide but more or less similar peroxide value in these samples.

The thiobarbituric acid (TBA) values (expressed as O.D. at 532 $\mathrm{nm}$ ) of ghee samples treated with OPP and BHA tabulated in the Table 3 .

TBA values in control were more as compared to the OPP and BHA treated samples. The OPP treated samples showed more TBA values than sample treated with BHA which may be due to interference of more color from the orange peel powder during preparation at temperature rather than development of red chromophore due to condensation of 2 moles of TBA and 1 mole of malondialdehyde. TBA test indicates the secondary products developed on lipid oxidation. Thiobarbituric acid reacts with malondialdehyde produced by lipid hydroperoxide decomposition to form a red chromophore with peak absorbance at $532 \mathrm{~nm}$. It is coloured complex phenomenon results from the condensation of 2 moles of TBA and 1 mole of malondialdehyde, under the combined effect of the temperature and $\mathrm{pH}$, though it is the quantity of malondialdehyde (in $\mathrm{mg}$ ) present in $1 \mathrm{~kg}$ of sample. Formation of TBA is a complex process. Malondialdehyde only forms from fatty acid chains containing at least three double bonds, like linolenic acid, to the exclusion of linoleic and oleic acid peroxide decomposition products. TBA is not specific to malondialdehyde because it can react with other aldehydes, browning reaction products, protein and sugar degradation products, amino acids and nucleic acids.

The sensory score of the treated and control ghee samples is presented in the Table 4. All the samples have scored more than 8 in terms of color, flavor, taste (except BHA) and OA. Samples treated with BHA, 2\% OPP and BHA have scored less for color,

Table 3 Thiobarbituric acid (TBA) value of ghee samples stored at $60 \pm 2^{\circ} \mathrm{C}$

\begin{tabular}{llllll}
\hline Treatment & \multicolumn{5}{c}{ Storage period, days } \\
\cline { 2 - 5 } & 0 & 4 & 8 & 12 & 0.206 \\
Control & 0.063 & 0.088 & 0.131 & 0.059 & 0.343 \\
OPP $(1 \%)$ & 0.029 & 0.034 & 0.039 & 0.063 & 0.105 \\
OPP $(1.5 \%)$ & 0.031 & 0.035 & 0.046 & 0.084 & 0.109 \\
OPP $(2 \%)$ & 0.035 & 0.036 & 0.049 & 0.053 & 0.089 \\
BHA $(0.02 \%)$ & 0.030 & 0.033 & 0.038 & \\
\hline
\end{tabular}

OPP: Orange peel powder; OA: Overall acceptability

Table 4 Effect of orange peel powder and BHA sensory quality of ghee at accelerated storage temperature $60 \pm 2{ }^{\circ} \mathrm{C}$

\begin{tabular}{lllll}
\hline Treatment & Color & Flavor & taste & OA \\
\hline Control & 8.38 & 8.38 & 8.33 & 8.17 \\
OPP $(1 \%)$ & 8.38 & 8.38 & 8.17 & 8.33 \\
OPP $(1.5 \%)$ & 8.25 & 8.25 & 8.33 & 8.17 \\
OPP $(2 \%)$ & 8.38 & 8.00 & 8.00 & 8.17 \\
BHA $(0.02 \%)$ & 8.13 & 8.13 & 7.83 & 8.17 \\
\hline
\end{tabular}


favor and taste, respectively. Sample treated with 1\% OPP had scored highest sensory score overall acceptability than all other samples.

Addition of natural extracts in dairy products is a newly emerging area (Rowan 2000) and has a vast potential (Shende et al. 2014). The research on use of orange peel extract as a natural antioxidant in ghee was not reported in the available scientific literature. The sensory data revealed that all the treated samples were in acceptable range and liked very much by panellist with sensory score of slightly above 8 and the score was close to control.

\section{Conclusions}

Development of peroxide value and thiobarbuturic acid (TBA) was less in ghee samples added with orange peel powder at accelerated condition $\left(60^{\circ} \mathrm{C} \pm 2\right)$ than BHA. The sensory data revealed that all the treated samples were in acceptable range and liked very much by panellist with sensory score of slightly above 8 and the score was close to control. The experimental data revealed that orange peel has got antioxidant potential and orange peel powder may be added to ghee as natural antioxidant for reducing oxidative deterioration of fat in ghee.

\section{References}

Abdelaal HA, Halaweish FT (2010) Food preservative activity of phenol compounds in orange peel extract (Citrus sinensis L.). Lucrari Stiintifice 53(15):233-240

Anagnostopoulou MA, Kefalas P, Papageorgiou VP, Assimopoulou AN, Boskou D (2006) Radical scavenging activity of various extracts and fractions of sweet orange peel (Citrus sinensis). Food Chem 94:19-25

Asha A, Manjunatha M, Rekha RM, Surendranath B, Heartwin P, Rao J, Magdaline E, Chitranayak Sinha (2015). Antioxidant activities of orange peel extract in ghee (butter oil) stored at different storage temperatures. J Food Sci Technol 52(12): 8220-8227

Beddows CG, Jagait C, Kelly MJ (2001) Effect of ascorbyl palmitate on the preservation of á- tocopherol in sunflower oil, alone and with herbs and spices. Food Chem 73:255-261
Bombardelli E, Morazzoni P (1993) The flavonoids: new perspectives in biological activities and theraputics. Chem Today 11:25-28

Choe E, Min DB (2006) Mechanisms and factors for lipid oxidation. Compreh Rev Food Sci 5:169-186

Gandhi K, Arora S, Pawar N, Kumar A (2013) Effect of vidarikand (extracts) on oxidative stability of ghee: a comparative studyresearch and reviews. J Dairy Sci Technol 2(1):1-11

Gharahkhani M, Ghorbani M, Gharahkhani A, SadeghiMahoonak A, Jibraeeli S, Ghassemi Y (2010) The effects of peel and fruit extracts of Thompson oranges on different stocks in preventing the oxidation of soybean oil. Quart Med Plants 2(38):55-66

Pawar N, Arora S, Bijoy RR, Wadhwa BK (2012) The effect of Asparagus racemosus (Shatavari) extract on oxidative stability of ghee, in relation to added natural and synthetic antioxidant. Int J D a i r y Technol 65(2):293-299

Peschel W, Ssnchez-Rabaneda F, Diekmann W, Plescher A, Gartza I, Jimenez $\mathrm{D}$ (2006) An industrial approach in the search of natural antioxidants from vegetable and fruitwastes. Food Chem97:137-150

Pukalskas A, Van Beek AT, De Waard P (2005) Development of a triple hyphenated HPLC radical scavenging detection-DAD-SPE-NMR system for the rapid identification of antioxidants in complex plant extracts. J Chromatogr A 1074:81-88

Rehman Z (2006) Citrus peel extract - a natural source of antioxidant. Food Chem 99:450-454

Rowan C (2000) Extracting the best from herbs. Food Eng Int 25:31-34 Shende S, Patel S, Arora S, Sharma V (2014) Oxidative stability of ghee incorporated with clove extracts and BHA at elevated temperatures. Int J Food Prop 17:1599-1611. doi:10.1080/10942912.2012. 752382

Wasnik PG, Menon RR, Surendra Nath B, Balasubramanyam BV, Manjunatha M, Shivram M (2017)Application of pixel intensity, fractal dimension and skeleton parameters for detection of adulteration of cow ghee with vanaspati derived from image analysis. Indian J of Dairy Science 70(3):331-337

Wasnik PG, Menon RR, Surendra Nath B, Balasubramanyam BV, Manjunatha M and Sivaram M (2017) Application of particle analysis and colour parameters for detection of adulteration of cow ghee with vanaspati derived from image analysis. Indian $\mathrm{J}$ of Dairy Science 70(2):200208

Yassari S,Yasari E (2013) Effects of extract of Thompson orange peels on the stability of canola oil. Int J Agric Crop Sci 5(4):450-454 